\title{
Digital Media Landscape in Brazil: Political (Mis)Information and Participation on Facebook and WhatsApp
}

\author{
PATRÍCIA ROSSINI \\ Department of Communication and Media, University of Liverpool, UK \\ VANESSA VEIGA DE OLIVEIRA \\ ÉRICA ANITA BAPTISTA \\ Department of Communication, Federal University of Minas Gerais, \\ Brazil

\section{JENNIFER STROMER-GALLEY} \\ School of Information Study, Syracuse University, USA
}

\begin{abstract}
WhatsApp is one of the most used messaging platforms across the globe and is particularly prominent in the Global South. Despite being a private messaging app, WhatsApp is becoming an important platform for political information and political talk, which raises concerns about the spread of misinformation on the platform. This paper presents comprehensive descriptive results of a national survey of internet users in Brazil, focusing on political information on social media. Our data shows that Brazilians are very active social media users, particularly on Facebook and WhatsApp, and consider these platforms very important to fulfill a myriad of political and informational aims. However, they also demonstrate great concern about the quality and accuracy of information circulating online. Despite finding significant differences in how these two platforms are used, the data
\end{abstract}

Patrícia Rossini: patricia.rossini@liverpool.ac.uk

Date submitted: 2021-01-07

Copyright (C) 2021 (Patrícia Rossini, Vanessa Veiga de Oliveira, Érica Anita Baptista, Jennifer StromerGalley). Licensed under the Creative Commons Attribution-NonCommercial-NoDerivatives 4.0 International Public License. Available at: http://journalqd.org 
suggests that WhatsApp is becoming central to how Brazilians have access to and engage with politics.

Keywords: political information, misinformation, WhatsApp, social media, Brazil

With a population of over 212 million and roughly $74 \%$ online, Brazil is the secondlargest Western country in terms of Internet users, and the third in the Global South, and represents one of the main markets for Facebook, Instagram, and WhatsApp. Of the 134 million Brazilians who are online, 99\% access the internet using smartphones and as many as $58 \%$ are mobile-only internet users (NIC.br, 2020).

In recent years, there has been considerable attention to the rise of WhatsApp, a private messaging application that allows one-to-one and group communication. WhatsApp has become an inherent part of Brazilian's everyday life, and the intensive use particularly in the Global South for purposes beyond personal messaging has driven much of the recent developments of the app: from allowing payments to the introduction of friction to reduce the spread of information. The lower costs of mobile internet access, along with the need to communicate across different operating systems, has been driving WhatsApp popularity as a channel for communication between business, services, and customers, as well as politicians and supporters. In the past few years - most notably since the 2018 Presidential Election, and more recently due to the Covid-19 pandemic - , the attention has shifted to political and informational uses of WhatsApp: for political mobilization and coordination, as well as a source of information (Avelar, 2019; Recuero et al., 2021; Rossini et al., 2020).

The focus on WhatsApp is not unwarranted: according to official figures provided by WhatsApp in 2017, the app had 120 million Brazilians users, only behind Facebook. Data from the Reuters Institute for the Study of Journalism shows a steep adoption of social media in general and WhatsApp in particular for news and information in the past couple 
of years - in 2020, social media platforms surpassed TV as the second main source of news in Brazil, and the use of smartphones for the same purpose now exceeds computers (Newman et al., 2020). Facebook is used for news by $54 \%$ of the population and WhatsApp by $48 \%$, despite having no "news feed". The same report places Brazilians as the most worried about false information among 40 countries, with $84 \%$ expressing concern about "what is real and what is fake on the internet" (Newman et al., 2020, p.18).

In this context, our study focuses on the political use of social media, with specific interest on political activities that take place on Facebook and WhatsApp in Brazil. We present descriptive data on a set of activities and behaviors, such as frequency of social media use, exposure to political content and cross-cutting exposure, use of Facebook and WhatsApp for political engagement and access to political news, perceptions about the quality and usefulness of political information, and exposure to misinformation in these platforms. We compare WhatsApp to Facebook because most of the research on social media and politics has focused on public social media platforms (Facebook and Twitter) and comparing activities and behaviors on WhatsApp to those on Facebook is helpful in understanding if, and how, a private messaging app is distinctive in affording political activities and engagement.

Our descriptive analysis of political and informational uses of digital platforms in Brazil help inform future research by showing the extent to which platforms such as Facebook and WhatsApp are used to discuss politics and seen as sources of information, as well as how the public perceives the problem of false content in these platforms and whether they trust information from such sources.

\section{Social Media, WhatsApp, and Political Participation}

After almost two decades since the first online social networking experiences, social media has become a ubiquitous part of everyday life for a majority of people living in Western Democracies. Due to its population, Brazil is naturally a large market for social 
media platforms, but the interest in how Brazilians use social media goes beyond the sheer number of users: internet users in Brazil are among the most active users of platforms such as Facebook and WhatsApp globally. Even on Twitter, Brazil represents the fourth largest market globally despite just over $10 \%$ of the online population using the platform. Given its user-base, the country has meaningful impact on social media policies and affordances, such as, for instance, being the first country where WhatsApp implemented forwarding curbs or its payment system.

As social media becomes an intricate part of people's daily lives, their use is increasingly shifting from social networking to entertainment, informational, and political purposes (Gil de Zúñiga et al., 2019; Newman et al., 2020). Despite not being primarily political spaces, social media platforms are consistently associated with political participation and engagement, as well as access to news and information.

In Brazil, scholars have investigated the use of social media by politicians and activists in several recent events, such as presidential elections (Recuero et al., 2021) and protests (Bastos et al., 2015; Mourão \& Chen, 2020). Recently, there has been a shift to WhatsApp given its prominent role in the current political context (Resende et al., 2019; Rossini et al., 2020). In this study, we focus on how Brazilians use different platforms when it comes to expressing their political opinions. Users routinely swing among different platforms instead of using just one and have distinct uses and expectations of each based on gratifications such as self-presentation and relationship management (Tandoc et al., 2019). Considering that there are typically generational gaps in social media use (Perrin \& Anderson, 2019), particularly for reasons related to politics (Gil de Zúñiga et al., 2019), we expect differences between age groups when it comes to platform choices for political expression.

RQ1) How do people in different age groups use different platforms to express political opinions? 
Social media use is regularly associated with relevant political outcomes, such as exposure to, and engagement with, cross-cutting perspectives and political conversation (Boulianne, 2015, 2019; Gil de Zúñiga et al., 2014). While there has been a vast body of research investigating such relationships, scholars have predominantly focused on the US and other European countries. Less is known about the extent to which Brazilians use social media for such purposes.

Even though most studies examining social media have been primarily focused on a single-platform, users are likely to be active on multiple channels and there is evidence that people recognize that different platforms have distinct 'roles' and affordances (Tandoc et al., 2019). While the role of social media in fostering a myriad of political outcomes has been vastly investigated (Boulianne, 2019), WhatsApp is still largely understudied despite some indication that the app may promote relevant political engagement, particularly among younger users (Gil de Zúñiga et al., 2019). Thus, we investigate how users perceive WhatsApp and Facebook as important for their political use.

RQ2) Are there differences in how important users perceive Facebook and Whats App for political purposes?

Comparing Facebook to WhatsApp, it is plausible to expect differences in both the frequency of exposure to political content and the frequency of cross-cutting exposure, given that these two platforms differ not only in informational affordances, but also in the type of social ties that users likely maintain. Several studies have examined the use of Facebook for news, suggesting that people tend to be exposed to information frequently, even if inadvertently, due to weak social ties (Nielsen \& Schrøder, 2014). Less is known about WhatsApp. While there is some evidence that people resort to the messaging app for news (Newman et al., 2020), WhatsApp does not have a news feed, which means that content about politics are primarily shared in one-to-one or group chats. Thus, we ask: 
RQ3) Are there differences between how often users are exposed to political content shared by friends on Facebook and WhatsApp?

Particularly with regards to cross-cutting exposure, strong social ties tend to share similar political views, while weak ties tend to contribute to information diversity (Barnidge, 2017; Eveland \& Hively, 2009). Facebook users tend to have several connections which are accumulated over time, which means they are likely to have both weak and strong ties sharing political content (Valenzuela et al., 2018), and scholars have found that social media use tends to expose people to diverse viewpoints (Barnidge, 2017). With regards to mobile messaging, evidence based on US data, Barnidge (2020) suggests that people are more likely to report perceived disagreement on social media platforms such as Facebook than on messaging apps (Barnidge, 2020). There is also some indication that people perceive mobile messaging applications as 'safer' discussion spaces than social media (Valeriani \& Vaccari, 2018). Hence:

H2) Users will be exposed to cross-cutting political views more frequently on Facebook than on WhatsApp.

Social media adds complexity to the contemporary media environment by blurring the boundaries between information producers, media outlets, political activists, and citizens. As a consequence of this crowded communication environment, there has been increased concern with the circulation of false or misleading information online-either shared accidentally by regular users or intentionally by coordinated campaigns and propaganda (Egelhofer \& Lecheler, 2019). There has been substantial international press coverage around misinformation in Brazil, particularly with regards to the weaponization of WhatsApp by political campaigns and coordinated groups (Avelar, 2019; Campos Mello, 2019; First Draft, 2019). However, the encrypted nature of WhatsApp makes it challenging for researchers to investigate to what extent users are exposed to such content. As such, users' perceptions about the quality, importance, and accuracy of information on 
WhatsApp become a relevant proxy to understand the extent to which false and misleading information affect people's experiences on the platform.

RQ4) How often do people come across misinformation on Facebook and WhatsApp?

RQ5) What are users' perceptions about the role of others in spreading misinformation on WhatsApp?

\section{Methods}

This study is based on a national survey of 1,615 internet users (18+), using demographic quotas for regions, age, gender, and education. The fieldwork was conducted by Ibope, a large Brazilian survey company, and combined online panel interviews $(\mathrm{N}=1,431)$ and random digit dial interviews ${ }^{1}(\mathrm{~N}=184)$ to obtain a sample that matches the general population of internet users - e.g., respondents who may primarily or exclusively have mobile internet access. The quotas were designed based on data from the annual national survey on the use of digital and communication technologies (TIC Domicílios). The data was collected from May 21 st to July 3rd, 2019. The sample was $53.3 \%$ female and $46.7 \%$ male, which mirrors the distribution of internet users in Brazil. As the difference between the desired quotas and the final sample were within the $2 \%$ margin of error, we did not use weights in our data ${ }^{2}$. Age was measured using an open-ended question $(M=36$, $\mathrm{SD}=13)$.

Among Brazilian internet users, it is estimated that $99 \%$ use a mobile device and that WhatsApp is installed on virtually all of them. Given our interests, our sample only

\footnotetext{
${ }^{1}$ RDD was used to supplement the online interviews and reach participants that are not in online panels. In this study, RDD reached respondents across all age groups and regions in the lowest education levels. ${ }^{2}$ Quotas were based on gender (two), region (five), age (four brackets), and education (three brackets). The only parameters with slight deviation from the quota estimates were region, with recruitment in the northeast being $-1 \%$ below and the south being $2 \%$ above the planned estimates, age, with all brackets presenting slight variations $(18-24,-2 \% ; 25-24,-1 \% ; 35-54,1 \% ; 55+: 2 \%)$.
} 
includes WhatsApp users, that is, participants were screened out of the survey if they did not use WhatsApp $(\mathrm{N}=65)$. Questions about Facebook were only asked to those who used it ( $89 \%$ of the sample). To our knowledge, this is the first large-scale national survey focusing on the political uses of social media and messaging apps in Brazil. The response rates for phone-based interviews were $26 \%$ based on AAPOR's RR1 standards, which cannot be applied to large non-probability panels (AAPOR, 2016).

Even though self-reported measures for social media and WhatsApp use are imperfect insofar as they rely on participant recall and may not reflect actual experiences, there is some evidence that self-reported measures of political activity on social media correlate with actual observed behavior (Guess et al., 2019).

Moreover, approaches such as using digital trace data cannot be used to study WhatsApp due to its end-to-end encryption. While scholars have focused on large-scale discussion groups to analyze actual conversations on WhatsApp, this approach cannot be scaled up to a national sample for a number of reasons: first, according to WhatsApp, most communication takes place between two people and the vast majority of users do not participate in large discussion groups. As such, large discussion groups are not representative of most people's experiences on WhatsApp. Second, the dynamics of largegroup discussions, where participants are likely to engage with unknown others or weak ties, are likely different than those among friends and family - either in one-to-one communication or groups. In these settings, some of the technical and social boundaries that characterize group membership among closer ties, such as avoiding social tension for leaving a group or removing a participant, are less prominent insofar as participants do not personally know, and hence might be socially disconnected from, their discussion peers (Mannell, 2020).

\section{Measures}

Frequency of Political Discussion. This item was measured using a 5-point Likert scale ranging from never (1) to every day or almost every day (5). The question asked: 
"Considering the past month, how often did you talk about politics and social issues (such as elections, government, education, violence, etc.) on Facebook/WhatsApp?". (M $\mathrm{MB}_{\mathrm{FB}}=$ $\left.3.08, \mathrm{SD}_{\mathrm{FB}}=4.59, \mathrm{M}_{\mathrm{WA}}=3.13, \mathrm{SD}_{\mathrm{WA}}=3.66\right)$.

Political Expression: Respondents were asked if they used social media (Facebook, Twitter, YouTube, Instagram) or WhatsApp to share their opinions about politics and current affairs. This was a binary question in which participants selected each platform they had used.

Importance for Political Purposes: Respondents were asked how Facebook / WhatsApp was important to "Follow political news $\left(\mathrm{M}_{\mathrm{FB}}=2.76 \mathrm{SDFB}_{\mathrm{FB}}=3.74, \mathrm{MwA}_{\mathrm{wA}}=2.57\right.$ $\left.\mathrm{SD}_{\mathrm{WA}}=2.62\right)$; Talk to like-minded people $\left(\mathrm{M}_{\mathrm{FB}}=2.65 \mathrm{SDFB}_{\mathrm{FB}}=1.02, \mathrm{M}_{\mathrm{WA}}=2.64 \mathrm{SDwA}\right.$ =3.53); Talk to people who have different opinions $\left(\mathrm{M}_{\mathrm{FB}}=2.52 \mathrm{SDFB}=1.05, \mathrm{MwA}_{\mathrm{FA}}=2.51\right.$ $\left.\mathrm{SDW}_{\mathrm{WA}}=2.60\right)$; Share your opinions about politics $\left(\mathrm{M}_{\mathrm{FB}}=2.55 \mathrm{SDFB}_{\mathrm{f}}=3.75, \mathrm{MwA}_{\mathrm{wA}}=2.55\right.$ SDwA $=3.56$ ); Learn about events, public demonstrations and protests about political and social issues that you care about $\left(\mathrm{M}_{\mathrm{FB}}=2.81 \mathrm{SD}_{\mathrm{FB}}=4.51, \mathrm{MwA}_{\mathrm{wA}}=2.68 \mathrm{SDwA}_{\mathrm{wA}}=1.05\right)$ ".

Frequency of Political Content Shared By Friends: This question verified the exposure to political content based on shares by friends and connections. Participants were asked: "In the past month, how often have you seen your friends share news and views on politics and social issues on Facebook/WhatsApp?". This item was measured using a 5point Likert scale ranging from never (1) to every day or almost every day (5). ( $\mathrm{M}_{\mathrm{FB}}=4.58$, $\mathrm{SD}_{\mathrm{FB}}=3.64, \mathrm{MwA}_{\mathrm{w}}=3.92, \mathrm{SDwA}_{\mathrm{WA}}=3.59$ ).

Frequency of Cross-Cutting Political Content: Participants were asked "Thinking about the content about politics and social issues your friends shared on Facebook/WhatsApp in the past month, how often do you generally disagree with the views expressed by them?". The item was measured with a 5 -item Likert scale ranging from never (1) to always (5). $\left(\mathrm{M}_{\mathrm{FB}}=3.32, \mathrm{SD}_{\mathrm{FB}}=0.91, \mathrm{MwA}=3.22, \mathrm{SD}_{\mathrm{WA}}=0.96\right)$. 
Perceived Exposure to Misinformation: To find out how much participants perceived to be exposed to false information, they were asked "How often do you see on Facebook/WhatsApp news about politics or social issues that you think are incorrect, false or misleading?". This item was measured using a 5-point Likert scale ranging from never (1) to always (5). $\left(\mathrm{M}_{\mathrm{FB}}=5.75, \mathrm{SD}_{\mathrm{FB}}=13.06, \mathrm{M}_{\mathrm{WA}}=6.39, \mathrm{SD}_{\mathrm{WA}}=16.43\right)$.

Perceptions About the Quality of the Information Environment. Participants answered questions about Facebook and WhatsApp using a 5-item Likert scale from strongly disagree (1) to strongly agree (5): "Useful to learn about breaking news" $\left(\mathrm{M}_{\mathrm{FB}}=4.22, \mathrm{SD}_{\mathrm{FB}}=7.21, \mathrm{MwA}_{\mathrm{A}}=4.32, \mathrm{SDwA}=5.72\right)$, "People shouldn't trust everything they read" $\left(\mathrm{M}_{\mathrm{FB}}=4.81, \mathrm{SD}_{\mathrm{FB}}=6.31, \mathrm{MwA}_{\mathrm{wA}}=4.49, \mathrm{SD}_{\mathrm{WA}}=2.69\right)$, "Some people share false or inaccurate news accidentally" $\left(\mathrm{M}_{\mathrm{FB}}=4.90, \mathrm{SDFB}=7.87, \mathrm{MwA}_{\mathrm{wA}}=4.52, \mathrm{SD}\right.$ wA $\left.=5.11\right)$, "Some people intentionally share false or inaccurate news" $\left(\mathrm{M}_{\mathrm{FB}}=4.57, \mathrm{SD}_{\mathrm{FB}}=7.17, \mathrm{MwA}_{\mathrm{w}}=4.48\right.$, $\left.\mathrm{SD}_{\mathrm{WA}}=5.11\right)$, "Politicians intentionally shares false or inaccurate news" $\left(\mathrm{MFB}_{\mathrm{FB}}=4.55, \mathrm{SDFB}\right.$ $\left.=7.91, \mathrm{MwA}_{\mathrm{WA}}=4.39, \mathrm{SD}_{\mathrm{WA}}=5.71\right)$.

Political Ideology was measured with a scale from left (1) to right (10), recoded as Left (1-3), Center (4-7), and Right (8-10).

Demographics. Age was measured using an open-ended question $(\mathrm{M}=36, \mathrm{SD}=13)$. Education was originally measured with nine items $(\mathrm{M}=4.69, \mathrm{SD}=1.59)$, ranging from pre-school (1) to holding a doctorate degree (9). For the analysis, we recoded Education as an ordinal variable with four items $(\mathrm{M}=1.43, \mathrm{SD}=0.84)$ : High School or Lower, Associate Degree/Some College, College, Advanced Degree ( $\mathrm{PhD}$, Masters).

\section{Results}

Before describing Brazilians' attitudes and behaviors on social media, we present the frequency of usage of Facebook and WhatsApp to give a sense of their centrality in the digital landscape. The majority of the sample reported using both platforms on a daily 
basis: 74\% reported using WhatsApp many times every day and another $22 \%$ reporting daily use, while Facebook is used several times a day by $62 \%$. Overall, the data supports the claim that Brazilians are generally intensive social media users. When demographic characteristics are taken into account, there are meaningful differences across platforms, with women being significantly more likely to report intense activity (i.e. several times a day) on Facebook, $X^{2}(4)=25.37, p<0.0001$ and slightly more likely to report intense activity on WhatsApp. Age is also associated with differences in frequency of social media use, with younger people (18-34) being more frequently active in both platforms. Among older users, WhatsApp is the most frequently used medium, with over $96 \%$ of those between 35 and 54 and $93 \%$ of those over 55 reporting at least daily use, with the majority in both groups being intensive users.

We were also interested in getting a sense of which platforms were used for political expression, beyond just Facebook and WhatsApp. Participants were asked whether they used social media to share their opinions about political or social issues. Answering our first research question, we find relevant differences across age groups when it comes to using social media to express political views, but the differences are only significant for Instagram, $X^{2}(3)=4.18, p=0.01$. Across platforms, WhatsApp and Facebook are the preferred venues for older users and Instagram is more used by those between 18 and 35 years of age.

Table 1. Political Expression on Social Media x Age Group.

\begin{tabular}{llllll}
\hline Age & \multicolumn{5}{c}{ Platform } \\
\cline { 2 - 6 } & WhatsApp & Facebook & Instagram & YouTube & Twitter \\
\hline $18-24$ & $36 \%$ & $46 \%$ & $23 \%$ & $9 \%$ & $12 \%$ \\
$25-34$ & $41 \%$ & $53 \%$ & $21 \%$ & $14 \%$ & $12 \%$ \\
$35-54$ & $43 \%$ & $51 \%$ & $14 \%$ & $11 \%$ & $14 \%$ \\
$55+$ & $46 \%$ & $44 \%$ & $4 \%$ & $11 \%$ & $8 \%$ \\
\hline
\end{tabular}

Note. Base: WhatsApp $=1,615 ;$ Facebook $=1,437$; Instagram $=1,121 ;$ YouTube $=1,502$; Twitter $=481$. 
Next, we turn to more specific political uses of Facebook and WhatsApp. Answering our second research question, we found significant differences in how participants perceive platforms to be important for following political news and learning about events, protests or demonstrations, with Facebook being perceived as more important than WhatsApp. However, we found no substantive differences in the extent to which participants perceive these two platforms when it comes to having homogeneous or heterogeneous conversations or sharing political opinions.

Table 2. Importance for Politics x Platform.

\begin{tabular}{|c|c|c|c|}
\hline & & Facebook & WhatsApp \\
\hline \multirow{4}{*}{$\begin{array}{l}\text { Follow political news } * * * \\
t(3018)=4.9, p<0.0001 \\
\mathrm{M}_{\mathrm{FB}}=2.76, M_{W A}=2.57\end{array}$} & Not Important & $16 \%$ & $21 \%$ \\
\hline & Somewhat Important & $20 \%$ & $23 \%$ \\
\hline & Important & $35 \%$ & $34 \%$ \\
\hline & Very Important & $29 \%$ & $23 \%$ \\
\hline \multirow{4}{*}{$\begin{array}{l}\text { Talk to like-minded people } \\
t(3014)=0.13 p=0.9 \\
\mathrm{M}_{\mathrm{FB}}=2.65, M_{W A}=2.64\end{array}$} & Not Important & $17 \%$ & $19 \%$ \\
\hline & Somewhat Important & $24 \%$ & $22 \%$ \\
\hline & Important & $35 \%$ & $36 \%$ \\
\hline & Very Important & $24 \%$ & $23 \%$ \\
\hline \multirow{4}{*}{$\begin{array}{l}\text { Talk to people who have different opinions } \\
t(3014)=0.35 p=0.7 \\
\mathrm{M}_{\mathrm{FB}}=2.52, M_{W A}=2.51\end{array}$} & Not Important & $21 \%$ & $23 \%$ \\
\hline & Somewhat Important & $26 \%$ & $24 \%$ \\
\hline & Important & $32 \%$ & $33 \%$ \\
\hline & Very Important & $21 \%$ & $20 \%$ \\
\hline \multirow{4}{*}{$\begin{array}{l}\text { Share your opinions about politics } \\
t(3008)=0.026 p=1 \\
\mathrm{M}_{\mathrm{FB}}=2.55, M_{W A}=2.55\end{array}$} & Not Important & $21 \%$ & $22 \%$ \\
\hline & Somewhat Important & $24 \%$ & $24 \%$ \\
\hline & Important & $32 \%$ & $32 \%$ \\
\hline & Very Important & $22 \%$ & $22 \%$ \\
\hline
\end{tabular}


Learn about events, public demonstrations and protests about political and social issues that you care about $* * *$ $t(3024)=3.6 p<0.001$ $\mathrm{M}_{\mathrm{FB}}=2.81, M_{W A}=2.68$

Not Important

Somewhat Important

Important

Very Important
$14 \% \quad 18 \%$

$20 \% \quad 23 \%$

$36 \% \quad 33 \%$

$30 \% \quad 26 \%$

Note. Base: WhatsApp $=1,615 ;$ Facebook $=1,437$.

Turning to exposure to political content shared by connections in each platform, Figure 1 presents the frequency that participants report seeing political content shared by friends and contacts on Facebook and WhatsApp. Respondents were significantly more likely to report seeing peers sharing political content on Facebook than on WhatsApp, $t(2962)=16, p<0.0001$, answering the third research question. On Facebook, 67\% reported seeing political information and opinions shared by their connections on a daily basis, with another $20 \%$ reporting being exposed to such content at least a few days per week. WhatsApp users reported a considerably lower frequency for daily exposure, $40 \%$, and a slightly higher frequency of weekly exposure.

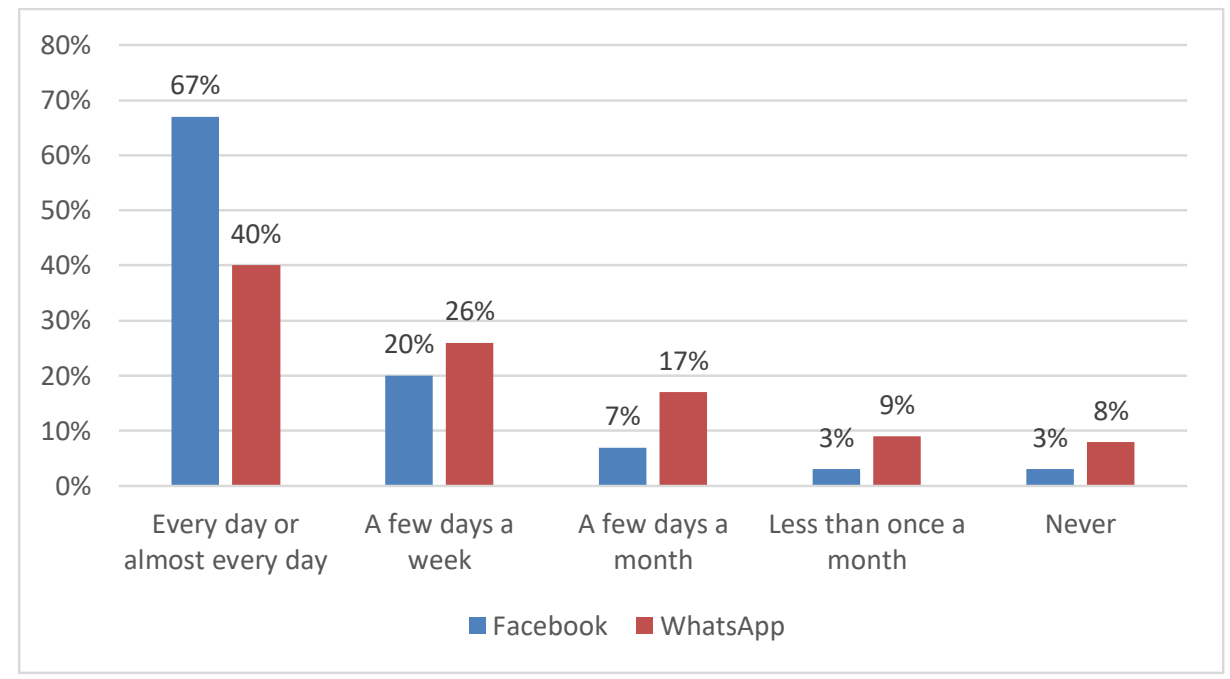

Figure 1. Perceived exposure to political content shared by connections.

Note. Base: WhatsApp =1,615; Facebook =1,437. 
To explore whether sociodemographic factors were associated with perceived exposure to political content shared by friends, controlling for frequency of platform use and political ideology, we fitted a OLS regression model controlling for education, gender (reference category: female), and age (as a continuous variable), using frequency of perceived exposure to political content posted by friends per platform as the dependent variable. Note that higher education levels predict exposure in both platforms, but gender and age are only predictors of WhatsApp political exposure, with male respondents and older respondents being more likely to report higher levels of exposure to political content shared by peers. WhatsApp users that identify as being either left- or right-wing are significantly more likely than centrists to report higher frequencies of perceived exposure to political content.

Table 3. Regression Model for Perceived Exposure to Political Content. Frequency of Exposure to Political Content

\begin{tabular}{lll}
\hline & Facebook & WhatsAp \\
\cline { 2 - 3 } (Intercept) & $2.18 * * *$ & $1.66 * * *$ \\
& $(0.17)$ & $(0.29)$ \\
Education & $0.09 * * *$ & $0.19 * * *$ \\
& $(0.02)$ & $(0.03)$ \\
Gender (Female $=1)$ & -0.05 & $-0.23 * * *$ \\
& $(0.05)$ & $(0.07)$ \\
Age & -0.00 & $0.01 *$ \\
& $(0.00)$ & $(0.00)$ \\
Freq. of Platform Use (FB/WP) & $0.46 * * *$ & $0.29 * * *$ \\
& $(0.03)$ & $(0.05)$
\end{tabular}




\begin{tabular}{lll} 
Ideology: Left & 0.01 & $0.31 * *$ \\
& $(0.07)$ & $(0.10)$ \\
Ideology: Right & 0.08 & $0.26 * * *$ \\
& $(0.05)$ & $(0.07)$ \\
\cline { 2 - 3 } $\mathrm{N}$ & 1434 & 1612 \\
$\mathrm{R} 2$ & 0.19 & 0.07 \\
\hline Note. & $* * * \mathrm{p}<0.001 ; * * \mathrm{p}<0.01 ; * \mathrm{p}<0.05$. &
\end{tabular}

Given the distinct nature of social networks presumably maintained on Facebook and WhatsApp, we hypothesized that respondents would be more likely to come across cross-cutting political views on Facebook. Figure 2 presents the results for frequency of perceived cross-cutting exposure. While percentages are relatively similar, respondents are significantly more likely to report disagreeing with opinions shared by their contacts on Facebook than on WhatsApp, $t(2863)=2.9, p=0.004\left(\mathrm{M}_{\mathrm{FB}}=3.32, \mathrm{MwA}_{\mathrm{WA}}=3.22\right)$.

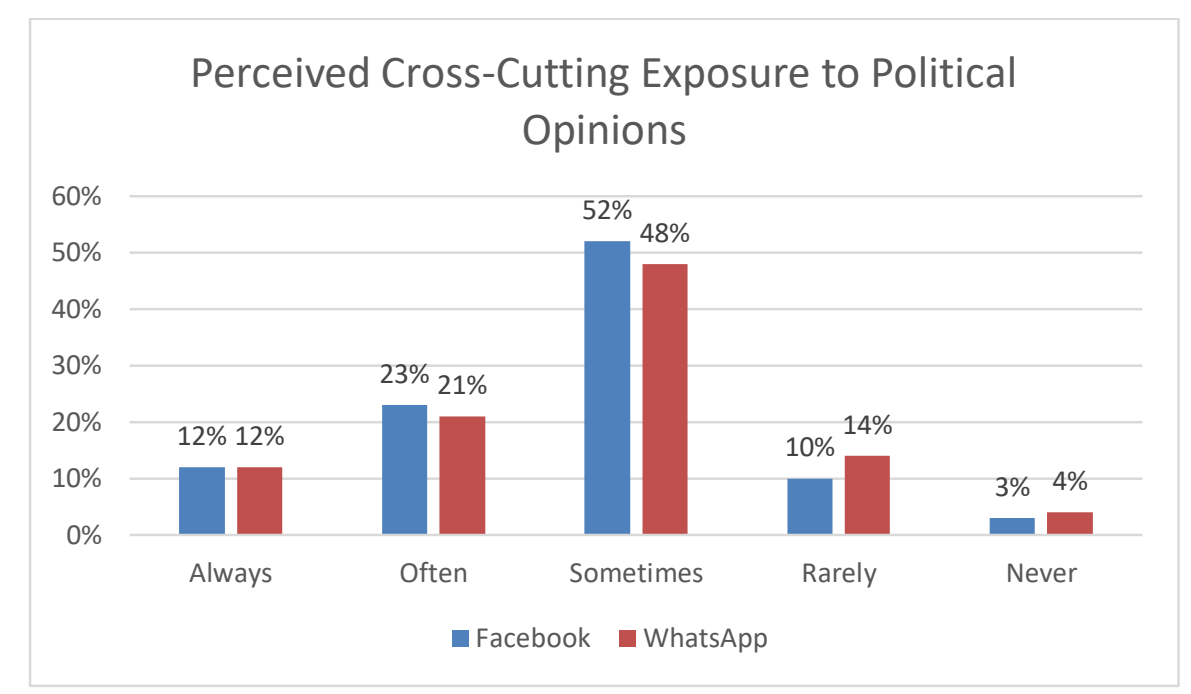

Figure 2. Perceived cross-cutting exposure to political opinions.

Note. Base: WhatsApp $=1,615 ;$ Facebook $=1,437$. 
Table 4 presents a OLS regression model to investigate whether cross-cutting exposure varies according to sociodemographic factors and frequency of platform use. While there are no differences in terms of gender or education, younger people are slightly more likely to report higher cross-cutting exposure on WhatsApp, and those who use Facebook more frequently are also more likely to perceive more frequent exposure to heterogeneous political views. In this model, ideology was not significant.

Table 4. Regression Model for Perceived Cross-Cutting Exposure.

\begin{tabular}{|c|c|c|}
\hline & Facebook & WhatsApp \\
\hline \multirow[t]{2}{*}{ (Intercept) } & $2.69 * * *$ & $3.11 * * *$ \\
\hline & $(0.18)$ & $(0.24)$ \\
\hline \multirow[t]{2}{*}{ Education } & 0.04 & 0.05 \\
\hline & $(0.03)$ & $(0.03)$ \\
\hline \multirow[t]{2}{*}{ Gender $($ Female $=1)$} & -0.08 & -0.07 \\
\hline & $(0.06)$ & $(0.06)$ \\
\hline \multirow[t]{2}{*}{ Age } & -0.00 & $-0.01 *$ \\
\hline & $(0.00)$ & $(0.00)$ \\
\hline \multirow[t]{2}{*}{ Freq. of Platform Use (FB/WP) } & $0.15 * * *$ & 0.04 \\
\hline & $(0.03)$ & $(0.05)$ \\
\hline \multirow[t]{2}{*}{ Ideology: Left } & 0.02 & 0.06 \\
\hline & $(0.08)$ & $(0.08)$ \\
\hline Ideology: Right & 0.08 & 0.05 \\
\hline
\end{tabular}




\begin{tabular}{lll} 
& $(0.06)$ & $(0.06)$ \\
\cline { 2 - 3 } $\mathrm{N}$ & 1390 & 1474 \\
$\mathrm{R} 2$ & 0.03 & 0.01 \\
\hline Note. ${ }^{* * *} \mathrm{p}<0.001 ; * * \mathrm{p}<0.01 ; * \mathrm{p}<0.05$ &
\end{tabular}

Shifting to perceptions around the prevalence of misinformation, participants were asked about how frequently they came across political news stories that they think are inaccurate, misleading or completely made up. Figure 3 presents the results. In general, respondents reported seeing falsehoods fairly frequently, with the majority of respondents (66\%) reporting that it happens often or always on Facebook, and 50\% saying it happens often or always on WhatsApp. Platforms differences are significant, with respondents being more likely to perceive a low quality informational environment on Facebook than on WhatsApp, $t(2971)=11, p<0.0001\left(\mathrm{M}_{\mathrm{FB}}=3.91, \mathrm{MwA}_{\mathrm{W}}=3.46\right)$.

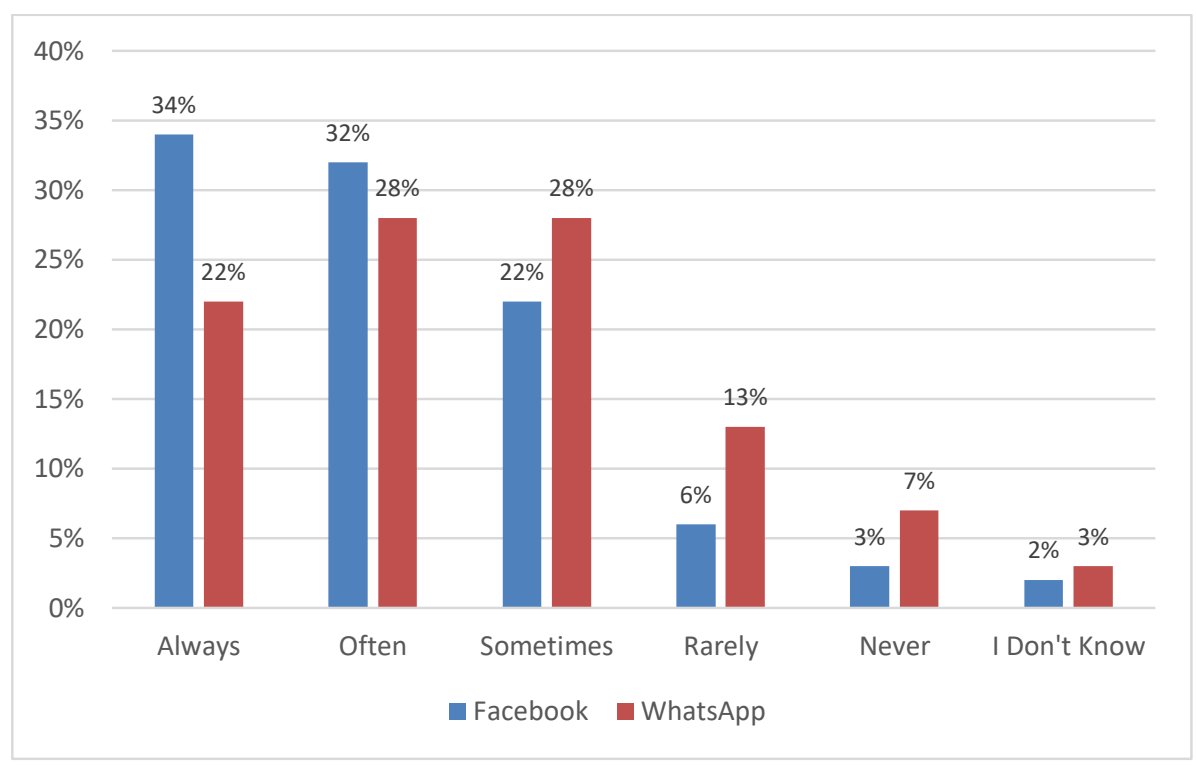

Figure 3. Exposure to false information per platform.

Note. Q: How often do you come across political news stories that you think are not fully accurate, misleading or completely made up? Base: WhatsApp =1,615; Facebook =1,437. 
We then used an OLS model to examine if perceived exposure to misinformation was associated sociodemographic factors and frequency of platform use. As perceptions of misinformation may be associated with one's preexisting political views (Rossini et al., 2020; Schulz et al., 2020), also included political ideology as a control. In this case, higher education levels predict higher perceived exposure to misinformation, as well as frequency of platform use. Gender and age are only significant for WhatsApp, with women and younger respondents being less likely to report frequent exposure to misinformation. As for political views, those who report being right-wing are more likely to perceive frequent exposure to misinformation in both platforms than centrists, but the same is not true for left-wing respondents.

Table 5. Regression Model for Perceived Exposure to Misinformation.

Frequency of Exposure to Misinformation

\begin{tabular}{lll}
\hline & Facebook & WhatsApp \\
\cline { 2 - 3 } (Intercept) & $2.51 * * *$ & $2.32 * * *$ \\
& $(0.20)$ & $(0.28)$ \\
Education & $0.09 * * *$ & $0.19 * * *$ \\
& $(0.03)$ & $(0.03)$ \\
Gender (Female $=1)$ & 0.10 & $-0.13 *$ \\
& $(0.06)$ & $(0.07)$ \\
Age & -0.00 & $-0.01 *$ \\
& $(0.00)$ & $(0.00)$ \\
Freq. of Platform Use (FB/WP) & $0.25 * * *$ & $0.17 * *$ \\
& $(0.03)$ & $(0.05)$ \\
Ideology: Left & 0.15 & 0.10
\end{tabular}




\begin{tabular}{|c|c|c|}
\hline Ideology: Right & $\begin{array}{l}0.18 * * \\
(0.06)\end{array}$ & $\begin{array}{l}0.20 * * \\
(0.07)\end{array}$ \\
\hline $\mathrm{N}$ & 1408 & 1564 \\
\hline $\mathrm{R} 2$ & 0.07 & 0.05 \\
\hline
\end{tabular}

To answer our fifth research question, we examine perceptions around the usefulness and the quality of the information environment, as well as the role of others in spreading falsehoods. We find that Facebook is perceived as significantly more useful to learn about breaking news than WhatsApp, even though a majority of respondents perceive both platforms to be at least somewhat useful. When it comes to trusting information, participants revealed comparable levels of concern about the accuracy of what is shared, with a vast majority strongly agreeing that people should not trust everything they read on both Facebook and WhatsApp. Lastly, with regards to intentionality of those who share false information, we found similar rates of agreement with the statement that some people share false or inaccurate news accidentally in both platforms. However, when it comes to intentional misinformation sharing, respondents were more likely to agree that some people and politicians intentionally used Facebook to share false or inaccurate information on purpose, with the differences being slightly bigger for politicians.

Table 6. Perceptions of Usefulness of Platforms and Sharing Behaviors.

\begin{tabular}{llll}
\hline & Perception & Platform & \\
\cline { 3 - 4 } & & Facebook & WhatsApp \\
\hline Useful to learn about breaking news & Strongly disagree & $6 \%$ & $9 \%$ \\
$* * *$ & Somewhat disagree & $6 \%$ & $9 \%$ \\
$\begin{array}{l}t(3035)=-6.7, p<0.0001 \\
\mathrm{M}_{\mathrm{FB}}=3.99, M_{W A}=3.69\end{array}$ & $\begin{array}{l}\text { Neither agree nor } \\
\text { disagree }\end{array}$ & $15 \%$ & $19 \%$ \\
\hline
\end{tabular}




\begin{tabular}{|c|c|c|c|}
\hline & Somewhat agree & $31 \%$ & $28 \%$ \\
\hline & Strongly agree & $43 \%$ & $34 \%$ \\
\hline People shouldn't trust everything & Strongly disagree & $4 \%$ & $5 \%$ \\
\hline $\begin{array}{l}\text { they read } \\
t(3035)=0.86, p=0.4\end{array}$ & Somewhat disagree & $2 \%$ & $2 \%$ \\
\hline $\mathrm{M}_{\mathrm{FB}}=4.43, M_{W A}=4.40$ & $\begin{array}{l}\text { Neither agree nor } \\
\text { disagree }\end{array}$ & $10 \%$ & $11 \%$ \\
\hline & Somewhat agree & $16 \%$ & $13 \%$ \\
\hline & Strongly agree & $68 \%$ & $69 \%$ \\
\hline Some people share false or & Strongly disagree & $4 \%$ & $5 \%$ \\
\hline $\begin{array}{l}\text { inaccurate news accidentally } \\
t(3021)=0.09, p=0.9\end{array}$ & Somewhat disagree & $3 \%$ & $3 \%$ \\
\hline $\mathrm{M}_{\mathrm{FB}}=4.26, M_{W A}=4.26$ & $\begin{array}{l}\text { Neither agree nor } \\
\text { disagree }\end{array}$ & $12 \%$ & $12 \%$ \\
\hline & Somewhat agree & $23 \%$ & $20 \%$ \\
\hline & Strongly agree & $57 \%$ & $59 \%$ \\
\hline Some people intentionally shares & Strongly disagree & $5 \%$ & $7 \%$ \\
\hline $\begin{array}{l}\text { false or inaccurate news } * * * \\
t(3037)=4.1, p<0.0001\end{array}$ & Somewhat disagree & $3 \%$ & $5 \%$ \\
\hline $\mathrm{M}_{\mathrm{FB}}=4.22, M_{W A}=4.04$ & $\begin{array}{l}\text { Neither agree nor } \\
\text { disagree }\end{array}$ & $13 \%$ & $16 \%$ \\
\hline & Somewhat agree & $23 \%$ & $21 \%$ \\
\hline & Strongly agree & $56 \%$ & $51 \%$ \\
\hline Politicians intentionally shares false & Strongly disagree & $5 \%$ & $8 \%$ \\
\hline $\begin{array}{l}\text { or inaccurate news } * * \\
t(3033)=3.7, p<0.001\end{array}$ & Somewhat disagree & $3 \%$ & $4 \%$ \\
\hline $\mathrm{M}_{\mathrm{FB}}=4.1, \quad M_{W A}=3.9$ & $\begin{array}{l}\text { Neither agree nor } \\
\text { disagree }\end{array}$ & $19 \%$ & $21 \%$ \\
\hline & Somewhat agree & $24 \%$ & $21 \%$ \\
\hline & Strongly agree & $48 \%$ & $45 \%$ \\
\hline
\end{tabular}

Note. Base: WhatsApp =1,615; Facebook $=1,437$. 


\section{Discussion}

This paper presents a descriptive account of how Brazilians use social media to engage in a myriad of political activities, as well as how they perceive the quality of the information environment on the two main platforms used in the country: Facebook and WhatsApp. Our data shows that Brazilians are very active social media users, and that Facebook and WhatsApp are consistently used by people in all age groups to share political opinions. We also find that younger adults also use Instagram for such purposes, confirming tendencies observed by other researchers that age matters for platform choice and political engagement (Boulianne, 2019; Gil de Zúñiga et al., 2019).

Focusing on Facebook and WhatsApp, users are more likely to be exposed to political information shared by connections on the former, and the same is true for crosscutting exposure. These results can be explained in a few different ways. First, having more weak ties is typically associated with exposure to political disagreement, and Facebook users tend to have more ties in general while WhatsApp users are likely to maintain contact with closer social peers, as the platform's primary use is texting (Rossini et al., 2020). Since WhatsApp relies on shared phone connections, it is likely that people use it to communicate with others with whom they maintain closer relationships, which can explain the lower likelihood of disagreement (Barnidge, 2017). Second, these findings can also reflect the distinct affordances of each platform. Facebook is centered in the news feed, has a formal presence of media outlets, and hence there are many opportunities for users to engage with and share information-as scholars have suggested, social sharing influences news selection on Facebook (Anspach, 2017) and social media is often associated with inadvertent news exposure (Barnidge, 2020). Our own data shows that Brazilians encounter political information and opinions shared by their connections significantly more on Facebook than on WhatsApp, which may also exacerbate the perception of cross-cutting content. 
Perhaps for similar reasons, Brazilians are more likely to perceive Facebook as a more useful resource to learn about what is happening around them, from breaking news to opportunities for political engagement. However, it is relevant to note that a majority of Brazilians deem WhatsApp as an important source of both political news and breaking news, aligned with the growing tendency of using the messaging app for informational purposes that has been observed by the Reuters Digital News Report (Newman et al., 2020). This is noteworthy because WhatsApp is not centered on a news feed nor has a formal presence of news outlets. As such, any information that circulates is being shared by regular users, from a multitude of sources, which can potentially exacerbate risks of users being misinformed. If Brazilians are increasingly turning to an encrypted messaging app to get political information, that should raise concerns with regards to both the quality and the accuracy of news they get — which are challenging to assess insofar as the platform is encrypted.

Despite using Facebook and WhatsApp for news and deeming the platforms important to learn about politics and current events, Brazilians believe they are very frequently exposed to false or misleading information - and this perception is higher on Facebook. Interestingly, even though it has been widely reported that right-wing misinformation prevails on WhatsApp (Campos Mello, 2019; First Draft, 2019), leftists were no more likely than centrists to report seeing misinformation, and right-wing respondents were significantly more likely to do so. It is possible that the prevalence of right-wing misinformation circulating among right-wing social circles affects the perception of exposure to false information. It is also possible that this is a reflection of President Jair Bolsonaro's rhetoric — using 'fake news' as a label to describe negative (even if factual) information about himself, his surrogates, or his government, a strategy that is often used by Donald Trump (Egelhofer \& Lecheler, 2019; Farkas \& Schou, 2018).

When it comes to who is responsible for sharing misinformation, Brazilians believe that while the majority of people may share false information accidentally, many also do so on purpose. As well, almost half of our respondents agree that politicians intentionally 
use social media to share false information. In all cases of intentional sharing, there is a perception that such situations happen more on Facebook than on Twitter, which may be related to the different types of ties maintained in each platform. Perhaps because of the presence of stronger social ties on WhatsApp, Brazilians were slightly, but significantly less likely to suggest that people intentionally spread misinformation on the platform.

Taken together, these findings provide a comprehensive account of how Brazilians use social media and WhatsApp to engage with political information and how differently they perceive the two main platforms used in the country: Facebook and WhatsApp. As such, they should inform future research investigating the patterns and behaviors elicited in this data, particularly with regards to how WhatsApp is becoming a central platform for political news and engagement.

This study has limitations. First, these measures reflect respondents' perceptions and not actual behaviors. Second, we cannot make causal claims on the nature of the relationships that we find using cross-sectional data, and the effort of this paper is descriptive. In spite of these, we believe this paper makes an important contribution by exploring how Brazilians use social media in general, and Facebook and WhatsApp in particular. Considering the relevance and prominence of the country in global debates about misinformation and political engagement online, the descriptive data in this study is useful for scholars interested in delving in any of the attitudinal and behavioral measures we presented.

Our data points to three main venues for future research: first, it provides evidence that users encounter substantive political difference on WhatsApp, suggesting that the uses of the app go well beyond 'texting' strong social ties and that those who consume information through one-to-one or group texts are likely exposed to a variety of views. However, our design does not account for the quality of such views, considering that users are themselves responsible for sharing information in the absence of a news feed. Future research should investigate what types of informational content circulate on WhatsApp, or 
what users perceive as information on the platform. Second, despite concerns with the quality and accuracy of information, Brazilians deem these platforms as relevant sources to learn about politics and breaking news. Future research needs to inquire how users negotiate these contradictory attitudes and make sense of what is accurate and what is not when using such platforms for political information. Third, the polarized political context of Brazil seems to affect both the extent to which participants see political information on WhatsApp and (mis)trust the quality of such information. The positive association between left and right ideologies in predicting exposure to political information may not be surprising insofar as partisans may be more likely to self-select into political discussions on WhatsApp, but the one-sided effects of right ideology on perceptions of misinformation may not necessarily be a reflection of the actual quality of the information environment and rather "spill over" effects of political rhetoric (Farkas \& Schou, 2018; Schulz et al., 2020). Future research must continue to take into account the potentially detrimental effects of anti-media discourses by populist politicians, as well as investigate why partisan perceptions are more prominent in the context of WhatsApp than on Facebook. In sum, our research demonstrates that Brazilians perceive, and use, WhatsApp and Facebook for different political purposes, warranting further investigation of the increasing use of private messaging applications to consume, engage, and spread political news.

\section{Funding}

The fieldwork for this research was supported by a "WhatsApp Misinformation and Social Science Research Award" granted to the authors as an unrestricted gift.

\section{References}

AAPOR. (2016). Standard definitions: final dispositions of case codes and outcome rates for surveys. 9th edition. (p. 81). AAPOR.

Anspach, N. M. (2017). The new personal influence: How our Facebook friends influence the news we read. Political Communication, 34(4), 1-17.

https://doi.org/10.1080/10584609.2017.1316329 
Avelar, D. (2019, October 30). WhatsApp fake news during Brazil election 'favoured Bolsonaro.' The Guardian. https://www.theguardian.com/world/2019/oct/30/whatsapp-fake-news-brazilelection-favoured-jair-bolsonaro-analysis-suggests

Barnidge, M. (2017). Exposure to political disagreement in social media versus face-toface and anonymous online settings. Political Communication, 34(2), 302-321. https://doi.org/10.1080/10584609.2016.1235639

Barnidge, M. (2020). Testing the inadvertency hypothesis: Incidental news exposure and political disagreement across media platforms. Journalism, 21(8), 1099-1118. https://doi.org/10.1177/1464884920915373

Bastos, M. T., Mercea, D., \& Charpentier, A. (2015). Tents, tweets, and events: The interplay between ongoing protests and social media. Journal of Communication, 65(2), 320-350. https://doi.org/10.1111/jcom.12145

Boulianne, S. (2015). Social media use and participation: A meta-analysis of current research. Information, Communication \& Society, 18(5), 524-538. https://doi.org/10.1080/1369118X.2015.1008542

Boulianne, S. (2019). Revolution in the making? Social media effects across the globe. Information, Communication \& Society, 22(1), 39-54. https://doi.org/10.1080/1369118X.2017.1353641

Campos Mello, P. (2019, October 9). WhatsApp admits to illegal mass messaging in Brazil's 2018. Folha de S.Paulo. https://www1.folha.uol.com.br/internacional/en/brazil/2019/10/whatsapp-admitsto-illegal-mass-messaging-in-brazils-2018.shtml

Egelhofer, J. L., \& Lecheler, S. (2019). Fake news as a two-dimensional phenomenon: A framework and research agenda. Annals of the International Communication Association, 43(2), 97-116. https://doi.org/10.1080/23808985.2019.1602782

Eveland, W. P., \& Hively, M. H. (2009). Political discussion frequency, network size, and "heterogeneity" of discussion as predictors of political knowledge and participation. Journal of Communication, 59(2), 205-224. https://doi.org/10.1111/j.1460-2466.2009.01412.x

First Draft. (2019, June 27). What 100,000 WhatsApp messages reveal about misinformation in Brazil. First Draft. https://firstdraftnews.org:443/latest/what100000-whatsapp-messages-reveal-about-misinformation-in-brazil/ 
Gil de Zúñiga, H., Ardèvol-Abreu, A., \& Casero-Ripollés, A. (2019). WhatsApp political discussion, conventional participation and activism: Exploring direct, indirect and generational effects. Information, Communication \& Society, 0(0), 1-18. https://doi.org/10.1080/1369118X.2019.1642933

Gil de Zúñiga, H., Molyneux, L., \& Zheng, P. (2014). Social media, political expression, and political participation: Panel analysis of lagged and concurrent relationships. Journal of Communication, 64(4), 612-634. https://doi.org/10.1111/jcom.12103

Guess, A., Munger, K., Nagler, J., \& Tucker, J. (2019). How accurate are survey responses on social media and politics? Political Communication, 36(2), 241-258. https://doi.org/10.1080/10584609.2018.1504840

Mannell, K. (2020). Plural and porous: Reconceptualizing the boundaries of mobile messaging group chats. Journal of Computer-Mediated Communication, 25(4), 274-290. https://doi.org/10.1093/jcmc/zmaa007

Mourão, R. R., \& Chen, W. (2020). Covering protests on Twitter: The influences on journalists' social media portrayals of left- and rightleaning demonstrations in Brazil. The International Journal of Press/Politics, 25(2), 260-280. doi: 10.1177/1940161219882653

Newman, N., Fletcher, R., Schulz, A., Andi, S., \& Nielsen, R. K. (2020). Reuters Institute Digital News Report (p. 112). Reuters Institute for the Study of Journalism. https://www.digitalnewsreport.org/Nielsen, R. K., \& Schrøder, K. C. (2014). The relative importance of social media for accessing, finding, and engaging with news: An eight-country cross-media comparison. Digital Journalism, 2(4), 472489. doi: $10.1080 / 21670811.2013 .872420$

Núcleo de Informação e Coordenação do Ponto BR. (2020). ICT Households (Survey on the use of information and communication technologies in Brazilian households, p. 344). Comitê Gestor da Internet no Brasil. https://www.cetic.br/pt/pesquisa/domicilios/publicacoes/

Perrin, A., \& Anderson, M. (2019, April 10). Share of U.S. adults using social media, including Facebook, is mostly unchanged since 2018. Pew Research Center. https://www.pewresearch.org/fact-tank/2019/04/10/share-of-u-s-adults-usingsocial-media-including-facebook-is-mostly-unchanged-since-2018/

Recuero, R., Soares, F., \& Vinhas, O. (2021). Discursive strategies for disinformation on WhatsApp and Twitter during the 2018 Brazilian presidential election. First 
Monday, https://doi.org/10.5210/fm.v26i1.10551

Resende, G., Melo, P., Sousa, H., Messias, J., Vasconcelos, M., Almeida, J., \& Benevenuto, F. (2019). (Mis)Information dissemination in WhatsApp: gathering, analyzing and countermeasures. The World Wide Web Conference on - WWW '19, 818-828. https://doi.org/10.1145/3308558.3313688

Rossini, P., Stromer-Galley, J., Baptista, E. A., \& Oliveira, V. V. de. (2020). Dysfunctional information sharing on WhatsApp and Facebook: The role of political talk, cross-cutting exposure and social corrections. New Media \& Society. https://doi.org/10.1177/1461444820928059

Valenzuela, S., Correa, T., \& Zúñiga, H. G. de. (2018). Ties, likes, and tweets: Using strong and weak ties to explain differences in protest participation across Facebook and Twitter use. Political Communication, 35(1), 117-134. https://doi.org/10.1080/10584609.2017.1334726

Valeriani, A., \& Vaccari, C. (2018). Political talk on mobile instant messaging services: A comparative analysis of Germany, Italy, and the UK. Information, Communication \& Society, 21(11), 1715-1731. https://doi.org/10.1080/1369118X.2017.1350730 